\title{
Multi-machine transient stability for railways
}

\author{
J. Laury \& M. H. J. Bollen \\ LTU, Luleå University of Technology, \\ Electric Power Engineering, Sweden
}

\begin{abstract}
This papers concern the replacement of Static Frequency Converters (SFC) by Rotary Frequency Converters (RFC) in Railway Power Supply Systems (RPSS) operating at $16 \frac{2}{3} \mathrm{~Hz}$. There is a need to investigate how such a system behaves with only one or with a small number of RFCs. This is of great importance as SFCs do not contribute to the inertia of the RPSS. Thus, the remaining RFCs have to keep the stability during a large disturbance.

Few studies investigate the stability of a RPSS and most of them study only the behaviour of a RFC in a converter station against an infinite bus. However, there are very few studies investigating a system with several RFCs in converter stations. Against this background, the aim of this paper is to present the results of a multi-machine transient stability study with several RFCs. Different cases have been investigated: regenerative braking of a train; a fault in the overhead contact line and a fault in the parallel $132 \mathrm{kV}$ line.

For the investigated cases the system with RFCs is stable but oscillations in the rotor angle swing occur due to no damping being modelled in the system.

Keywords: rotary converter, $16 \frac{2}{3} \mathrm{~Hz} A C$ railways, multi-machine transient stability.
\end{abstract}

\section{Introduction}

In Sweden, the Railway Power Supply System (RPSS) is operated at $16 \frac{2}{3} \mathrm{~Hz}$ and fed from the $50 \mathrm{~Hz}$ public grid through converter stations. The RPSS does not have any power generation, all electrical power is obtained from the public grid. A converter station consists of one or more Rotary Frequency Converters (RFC) and Static Frequency Converters (SFC). 
The RFC is a three phase synchronous motor and a single phase synchronous generator with the same pole pair number $p$. The motor and generator are mounted on the same shaft. The power is transferred from the motor via the shaft to the generator. The electrical frequencies are given by (1) according to [1,2]. The RFC can be overloaded for a limited time, and has the possibility to handle reverse power flow. However, they have long start up times and the phasing-in procedure can be complicated [3].

The SFC is controlled to mimic the behaviour of a RFC, so they can be easily installed and operated together with existing RFCs in. However the SFC do not contribute to the inertia of the RPSS. The remaining RFCs maintain the RPSS stable by transferring kinetic energy from the public grid.

Another difference is that the SFC generally cannot be overloaded and that some of them cannot cope with reverse power flow, i.e power from the RPSS to the $50 \mathrm{~Hz}$ grid, due to their design and construction.

$$
\begin{array}{r}
\text { Motor: } f_{50 \mathrm{~Hz}}=3 p \cdot f_{\text {mech }} \\
\text { Generator: } f_{16 \frac{2}{3} \mathrm{~Hz}}=p \cdot f_{\text {mech }}
\end{array}
$$

There are a limited number of study on stability of $16 \frac{2}{3} \mathrm{~Hz}$ RPSS. Most of them focus on a Single Machine Infinite Bus system. Reference [4] investigates the stability of the RPSS with a parallel $132 \mathrm{kV}$ single phase line of $16 \frac{2}{3} \mathrm{~Hz}$ i.e a centralized system. The $132 \mathrm{kV}$ supply line is connected to the Overhead Contact Line (OCL) through power transformers, whereas the OCL is fed from the public grid through frequency converters, cf. Figure 1.

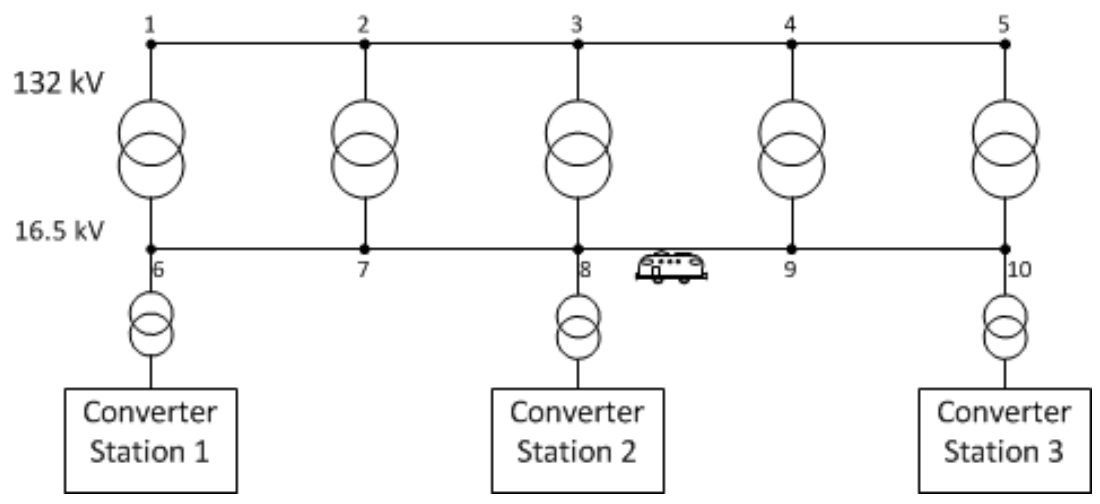

Figure 1: An example of a centralized system.

The system in [4] has been subjected to faults in the $132 \mathrm{kV}$ supply line and to regenerative braking. It was concluded that a converter station with both SFC and RFC maintains stability for proper fault clearing times. Critical fault clearing times have been calculated. The critical clearing time is the time available to the protection system to clear the fault before the system becomes unstable. 
Reference [5] provides a general description of a RFC. It describes the transient stability of parallel operation of several RFCs in a converter station, and studies the stability for regenerative braking.

However, neither study considers the behaviour of several converter stations. Therefore there is a need for knowledge to study the behaviour of the converters in several stations during a large disturbance. These studies are essential for setting requirements on the protection and they provide essential insight in the stability of the system.

This paper presents the behaviour of several RFC in a $16 \frac{2}{3} \mathrm{~Hz}$ RPSS during different disturbances. One of the main assumptions made during the studies is that the total rotating mass of a RFC is on the generator. The generator is seen a special turbine from the $16 \frac{2}{3} \mathrm{~Hz}$ side. The single-axis model of a turbine can be applied [4]. Furthermore, this paper describes how the RFCs are modelled and what considerations are taken when studying multi-machine transient stability for a RPSS of $16 \frac{2}{3} \mathrm{~Hz}$.

\section{Models}

\subsection{Models of the RFC}

\subsubsection{Static model}

The RFC is synchronously connected to the $50 \mathrm{~Hz}$ public grid, which implies that the single-phase voltage angle is one third of the $50 \mathrm{~Hz}$ grid voltage angle c.f. (2). This implies that there is no need for frequency control in the RPSS [6].

$$
\theta_{16 \frac{2}{3}}=\frac{1}{3} \theta_{50}
$$

The static model of RFC used in this paper originates from [6,7]. The relationship between the $50 \mathrm{~Hz}$ grid and $16 \frac{2}{3} \mathrm{~Hz}$ grid is described by (3)-(6) and Table 1 explains the variables used.

$$
\begin{gathered}
U^{g}=16.5-\frac{Q_{G}}{\# c o n v \cdot k_{q}} \\
\theta^{0}=\theta^{50}-\frac{1}{3} \cdot \arctan \frac{X_{50} \cdot P_{G}}{\left(U_{m}\right)^{2}+X_{50} \cdot Q_{50}} \\
\psi=-\frac{1}{3} \cdot \arctan \frac{X_{q}^{m} \cdot \frac{P_{G}}{\# \text { conv }}}{\left(U_{m}\right)^{2}+X_{q}^{m} \cdot \frac{Q_{50}}{\# c o n v}}-\arctan \frac{X_{q}^{g} \cdot \frac{P_{G}}{\#_{c o n v}}}{\left(U_{g}\right)^{2}+X_{q}^{g} \cdot \frac{Q_{G}}{\# c o n v}} \\
\theta=\theta^{0}+\psi\left(P_{G}, Q_{G}, U\right)
\end{gathered}
$$

In a converter station consisting of the same type RFC, the of reactive power and active power injected to the catenary, and the of absorbed reactive power is assumed to be equally divided over RFCs. The output voltage at the converter station is kept at $16.5 \mathrm{kV}$ at the point of connection to the catenary. The voltage can 
Table 1: Explanation of denotations of rotary converter equations.

\begin{tabular}{ll}
\hline Denotation & Description \\
\hline$\theta^{50}[\mathrm{rad}]$ & No-load phase angle, $50 \mathrm{~Hz}$ side \\
$X_{q}^{m}[\Omega]$ & Qadrature reactance motor \\
$X_{q}^{g}[\Omega]$ & Quadrature reactance generator \\
$U^{m}[\mathrm{kV}]$ & Voltage at motor side \\
$U^{g}[\mathrm{kV}]$ & Voltage at generator side \\
$\#$ conv & Number of converters \\
$\psi[\mathrm{rad}]$ & Phase angle difference between $50 \mathrm{~Hz}$ side \\
& and 16.7 Hz side of converter \\
$P_{G}[\mathrm{MW}]$ & Generated active power at generator side \\
$Q_{G}[\mathrm{MVAr}]$ & Generated reactive power at generator side \\
$Q_{50}[\mathrm{MVAr}]$ & Absorbed reactive power \\
\hline
\end{tabular}

drop if the power demand is high as described by (3) and (5). Equation (5) gives also the single phase terminal voltage shift, when the converter station is unloaded, and (6) described the single phase voltage angle at the generator side [7,8].

\subsubsection{Dynamic model}

The RFC consist of a motor and generator mounted on the same shaft. Assuming the shaft is stiff and the total rotating mass of the RFC is on the generator, the RFC can be modelled as a special turbine [4]. Thus, a regular model of a synchronous machine can be applied

During a transient period the synchronous machine can be modelled as voltage source behind its transient reactance $[9,10]$. The motion of the rotor can be described with a set of differential equation, i.e state variables, based on Newtons second law of motion, c.f. (7).

$$
\frac{H}{\pi f_{0}} \frac{d^{2} \delta}{d t^{2}}=\left(P_{m}-P_{e}\right)
$$

where $\delta[\mathrm{rad}]$ is the position of the rotor; $H[\mathrm{~s}], P_{m}[\mathrm{~W}]$ and $P_{e}[\mathrm{~W}]$ are the inertia constant, mechanical power and electrical power. The inertia constant is one of the most important quantities in a power system: it determines how long it would take to bring a generator from synchronous speed to standstill. It also determines how sensitive the system is for a sudden change in power production or consumption. 


\subsection{Multi-machine system model}

In order to do multi-machine transient stability studies, the voltages magnitudes and phase angles of a power system have to be known prior to the event, and obtained by a load-flow study. An event can be a short-circuit fault (typically just called 'fault') or regenerative braking. In order to simplify the study, following assumptions are made $[9,10]$.

- Loads are converted to equivalent admittance to ground.

- Constant flux in the generator, i.e saliency effects are neglected.

- The damping of the machines and asynchronous power are neglected.

- RFCs in the same converter station are coherent.

- The mechanical power is constant during the transient phenomena.

Assuming that the train speed is $150 \mathrm{~km} / \mathrm{h}$, the train will move less than 500 meters, which is $1 \%$ of $50 \mathrm{~km}$ distance between the stations. Thus the movement of the train is not considered during the event.

With the result of the load-flow study the current of machines have been calculated and the transient voltage is obtained. The loads that are converted to admittance are inserted in the admittance matrix $Y_{n n}$, where $n$ is the number of nodes, $n=1 \ldots j$. Adding the $m$ generator nodes to the system, $m=1 \ldots j$, the following relation is obtained:

$$
\left[\begin{array}{c}
\mathbf{I}_{\mathbf{n}} \\
\mathbf{I}_{\mathbf{m}}
\end{array}\right]=\left[\begin{array}{cc}
\mathbf{Y}_{\mathrm{nn}} & \mathbf{Y}_{\mathrm{nm}} \\
\mathbf{Y}_{\mathbf{n m}}^{\mathrm{t}} & \mathbf{Y}_{\mathrm{mm}}
\end{array}\right]\left[\begin{array}{c}
\mathbf{V}_{\mathbf{n}} \\
\mathbf{E}_{\mathbf{m}}^{\prime}
\end{array}\right]
$$

To reduce the complexity of the problem Kron reduction formula is used. This implies that all currents are set to zero except the generator currents. Thus, the admittance matrix is reduced to a size of $m \times m$, c.f. (9).

$$
\mathbf{Y}_{\text {red }}=\mathbf{Y}_{\mathbf{m m}}-\mathbf{Y}_{\mathbf{n m}}^{\mathrm{t}} \mathbf{Y}_{\mathbf{n n}}^{-1} \mathbf{Y}_{\mathbf{n m}}
$$

The electrical power of the generators can be expressed by (10).

$$
P_{e i}=\sum_{j=1}^{m}\left|E_{i}^{\prime}\right|\left|E_{j}^{\prime}\right|\left|Y_{i j}^{r e d}\right| \cos \left(\theta_{i j}-\delta_{i}+\delta_{j}\right), \quad i=1 \ldots m
$$

During steady state, the mechanical power and electrical power are equal. During the event, the admittance matrix changes and the system is not longer in steady state. By applying (7) and transform into state variable model, the swing equation describing the motion of the rotor is expressed by Equations (11) (12), where $\dot{\omega}[\mathrm{rad} / \mathrm{s}]$ is the deviation from synchronous speed. In this case the synchronous speed is $\omega_{s}=2 \pi f_{s}$, where $f_{s}=16 \frac{2}{3} \mathrm{~Hz}$.

$$
\begin{gathered}
\frac{d \delta_{i}}{d t}=\dot{\omega}_{i} \\
\frac{d \dot{\omega}_{i}}{d t}=\frac{\pi f_{0}}{H_{i}}\left(P_{\mathrm{m} i}-P_{\mathrm{e} i}\right)
\end{gathered}
$$




\section{Simulations and results}

\subsection{Simulations}

The system simulated is represented in Figure 1; the distance between the transformers is $50 \mathrm{~km}$ and distance between converter stations is $100 \mathrm{~km}$.

The impedance of the OCL is $0.2+j 0.2 \Omega / \mathrm{km}$ and $0.051+j 0.031 \Omega / \mathrm{km}$ for the $132 \mathrm{kV}$ supply line [7,8].

Converter station 1 , is the infinite bus of the system installed with 5 RFCs of type Q48/Q49, and the rest of the stations have one installed RFC each of the same type. The train is assumed to consume $8 \mathrm{MW}$.

Simulations are done in GAMS and MatLab, where in GAMS the load-flow calculation is done and in MatLab the dynamical part is solved. The results presented are from four different cases, and present the phase angle of converter station 2 and 3 relative to the infinite bus. The cases investigated are:

- Case 1: Continuous regenerative braking, single step from $8 \mathrm{MW}$ consumption to $8 \mathrm{MW}$ generation.

- Case 2: Regenerative braking for 2 second, single step from 8 MW consumption to $8 \mathrm{MW}$ generation. The braking stops after 2 seconds, single step from $8 \mathrm{MW}$ to zero.

- Case 3: Phase-to-ground fault in the $132 \mathrm{kV}$ supply line, between node 2 and 3. Different clearing times.

- Case 4: Phase-to-ground fault in the $16.5 \mathrm{kV}$ OCL, between node 7 and 8 .

\subsection{Results}

The figures represent the relative phase angle of each converter station, dotted line $\delta_{21}$ and solid line $\delta_{31}$, of converter station 2 and 3 against converter station 1.

When the train brakes the phase angles will increase to reach their maximum and then decrease, and the converter stations swing together which can be seen in Figures 2 through 4 and in Figure 6. Thus the system finds a new stable point of operation. The curves are similar due to the converter stations are of the same type, and the shift between the curves is due to the difference in distance between the converter station and the event.

When the fault occurs in the $132 \mathrm{kV}$ supply line and it is cleared in $0.86 \mathrm{~ms}$ the system remains stable, which can be seen in Figure 4. However if the fault is cleared in $0.866 \mathrm{~ms}$ the system becomes unstable and the machines lose synchronism, c.f. Figure 5.

\section{Conclusion and discussions}

In all cases investigated the system is shown to be stable. However in Case 3 it is shown that the clearing time of the fault cannot be longer than $0.86 \mathrm{~ms}$ The converter stations lose synchronism when the fault-clearing time exceeds this critical fault-clearing time, as was shown in Figure 5. 


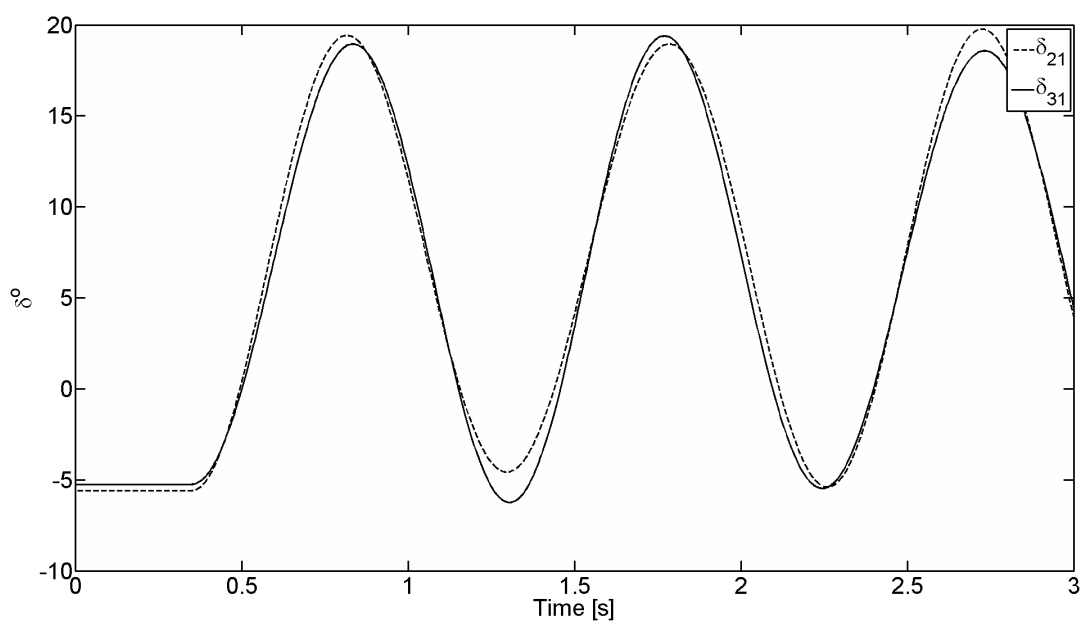

Figure 2: Case 1. Phase angle of converter station 2 (dotted line) and 3 (solid line) relative to station 1 during continuous regenerative braking.

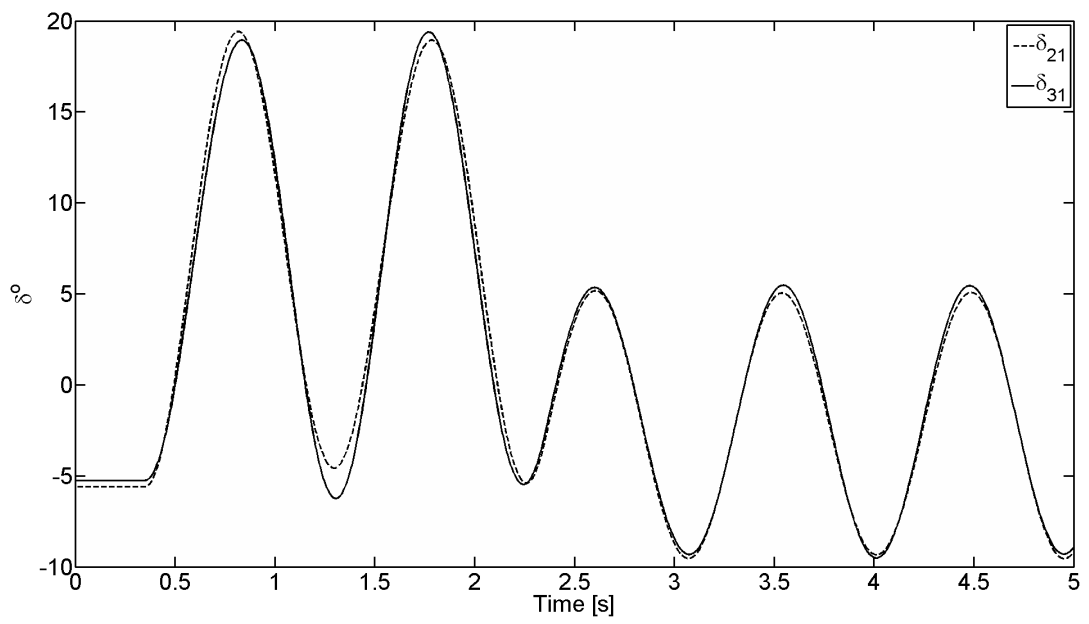

Figure 3: Case 2. Phase angle of converter station 2 (dotted line) and 3 (solid line) relative to station 1 during 2 seconds of regenerative braking.

If the fault occurred in the OCL, as in Case 4, the system sees a sudden increase of power and the rotor angle decreases followed by a rotor-angle oscillation. Here lies also the most challenging part of RPSS protection. The protection equipment must be able to distinguish between a fault and a train accelerating; in case of a fault that fault should be cleared within the critical fault-clearing time.

Thus a fault in the $132 \mathrm{kV}$ parallel supply line is more severe to the system than a fault in the OCL, as most of the power is transferred via the $132 \mathrm{kV}$ line. 


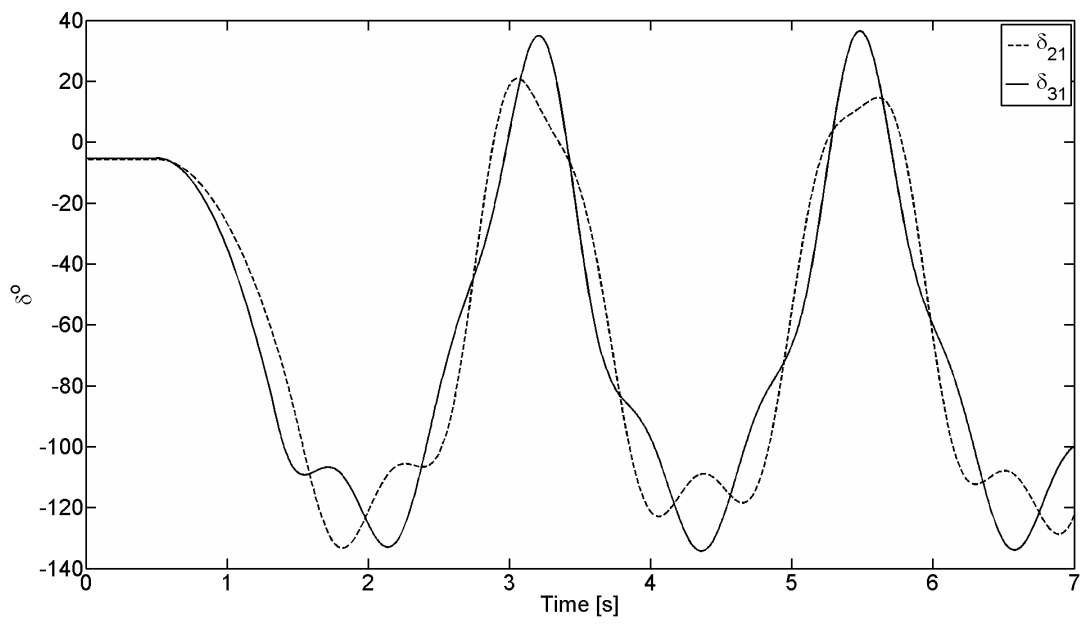

Figure 4: Case 3. Phase angle of converter station 2 (dotted line) and 3 (solid line) relative to station 1 during a fault in the $132 \mathrm{kV}$ line, cleared at $0.86 \mathrm{~ms}$.

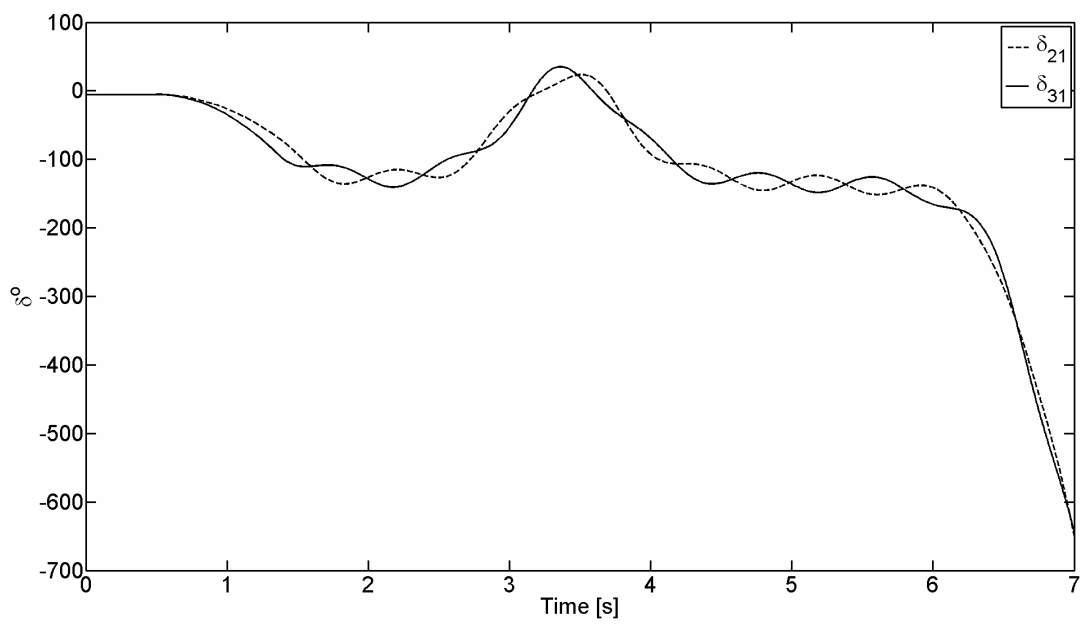

Figure 5: Case 3, unstable. Phase angle of converter station 2 (dotted line) and 3 (solid line) relative to station 1 during a fault in the $132 \mathrm{kV}$ line, cleared at $0.866 \mathrm{~ms}$.

The model has its limitation regarding regenerative braking. The fact is that the position of the train changes during the braking which implies that the admittance matrix also changes. However, it has been assumed that impact is negligible. When the train starts braking the power regenerated will be at its highest for just a few seconds after which it will start to decrease to zero. The system will come to a steady state, and this is indicated in Figure 3. 


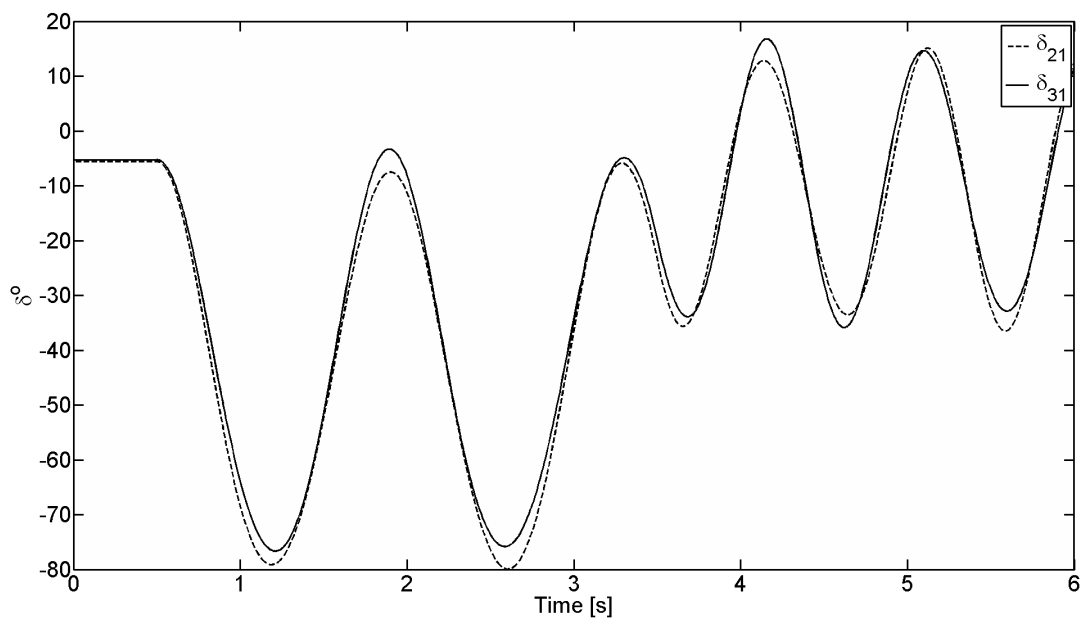

Figure 6: Case 4. Phase angle of converter station 2 (dotted line) and 3 (solid line) relative to station 1 during a 2 second fault in the $16.5 \mathrm{kV}$ line, cleared at $2.25 \mathrm{~s}$.

The model used gives substantial information how converter stations installed with only RFC behaves during regenerative braking or disturbances. Understanding of that behaviour is an important first step in studying the impact of the replacement of RFCs by SFCs on the stability of RPSS. The next step is to investigate the dynamics of systems with a both RFC and SFC. Such a system will behave differently than a system with only RFC, as was studied in this paper. The impact of this on the overall system stability is still not understood.

\section{References}

[1] Danielsen, S., Electric Traction Power System Stability. Ph.D. thesis, Norwegian University of Science and Technology, 2010.

[2] Heising, C., Fang, J., Bartelt, R., Staudt, V. \& Steimel, A., Modelling of rotary converter in electrical railway traction power-systems for stability analysis. Electrical Systems for Aircraft, Railway and Ship Propulsion, 3, pp. 1-6, 2010.

[3] Östlund, S., Electric Railway Traction. School of Electrical Engineering, Royal Insitute of Technology: Stockholm, 2012.

[4] Olofsson, M., Undersökning av transient stabilitet $i$ matningssytem för elektrisk tågdrift. Master thesis, Kungliga Tekniska Högskolan, 1989.

[5] Biesenack, H. \& Schimdt, P., Die dezentrale Bahnenergieversorgung von 16 $\frac{2}{3}-H z$-Einphasen-wechselstrombahnen über Synchron-SynchronUmformer. Elektrische Bahnen, 11, pp. 178-181, 1991. 
[6] Olofsson, M., Optimal Operation of the Swedish Railway Electrical System - An application of Optimal Power Flow. Ph.D. thesis, Royal Institute of Technology, 1996.

[7] Abrahamsson, L., Railway Power Supply Models and Methods for Long-term Investment Analysis, Licentiate thesis, Royal Institute of Technology, 2008.

[8] Laury, J., Optimal Power Flow for an HVDC Feeder Solution for AC Railways: Applied on a Low Frequency AC Railway Power System, Master's Thesis, Royal Institute of Technology, 2012.

[9] Saadat, H., Power System Analysis. PSA Publishing, 3rd edition, 2010.

[10] Kundur, P., Power System Stability and Control. McGraw-Hill, Inc, 1994. 